\title{
Psychogenic Polydipsia-Associated Water Intoxication: A Case Report
}

\author{
Murat Tolga Avşar, (1) Mehmet Toptaş, (i) Ibrahim Akkoç
}

Department of Anesthesiology and Intensive Care Unit, Haseki Training and Research Hospital, Istanbul, Turkey

\begin{abstract}
Psychological polydipsia can be seen in up to $20 \%$ of the patients with psychiatric disorders. Polydipsia can result in hyponatremia, defined as water intoxication that can be fatal. Headache, nausea, seizure, and convulsions may be observed in water intoxication cases. We report a case of a 28-year-old patient with schizophrenia and encephalopathy who developed hyponatremia. The patient had hyponatremia, seizures, and cerebral edema due to water intoxication. The patient was treated intensively and discharged from the internal medicine service on day 3.

Keywords: Hyponatremia; polydipsia; water intoxication.
\end{abstract}

C ompulsive drinking or psychogenic polydipsia refers to excessive, uncontrolled, water intake unrelated to the sensation of thirst. Primary or psychological polydipsia can be seen in $6 \%-20 \%$ of the patients with psychiatric problems ${ }^{[1]}$. Development of water intoxication has been indicated in $1 \%-5 \%$ of the patients ${ }^{[2]}$.

Though polydipsia is a dangerous condition that is commonly seen in patients with schizophrenia, it is often overlooked ${ }^{[3]}$. In the short term, it may cause excessive fluid consumption that may lead to water intoxication characterized by dilutional hyponatremia resulting in inadequate elimination of excess fluid from the kidneys, leading to confusion and seizures ${ }^{[4,5]}$. Water intoxication, as first described by Barahal in 1938, may progress with the symptoms of hyponatremia as headache, nausea, seizure, and coma that may lead to death ${ }^{[6,7]}$.

\section{Case Report}

An 18-year-old female patient with a height of $165 \mathrm{~cm}$ and weight of $58 \mathrm{~kg}$ was brought to our emergency service due to attacks of seizure and loss of consciousness. On evaluation, she was observed to suffer from attacks of seizure and was administered $4.5 \mathrm{mg}$ intravenous midazolam by emergency service physicians. Since her seizures could not be prevented, and she had shallow respiration, the patient was sedated, curarized, and then intubated with an orotracheal tube. On cerebral computerized tomography, cerebral edema was detected. She was then admitted to the intensive care unit (ICU). Some remarkable biochemical test results of the patient were as follows: serum sodium, 107 $\mathrm{mmol} / \mathrm{L}$; potassium, $3.51 \mathrm{mmol} / \mathrm{L}$; chlorine, $79 \mathrm{mmol} / \mathrm{L}$; and calcium, $7.68 \mathrm{~g} / \mathrm{dL}$. Antidiuretic hormone (ADH) level could not be measured. Hemogram and other biochemical test results were within normal limits. It was discovered that she was regularly using antipsychotic medication with the diagnosis of schizophrenia. When the anamnesis was deepened, it was also learned that the patient traveled from Japan to Istanbul and thought that she was poisoned by the resident hotel staff, so she had ingested excessive amounts of water as a precaution. Empty water carboys were found

Correspondence (iletişim): Murat Tolga Avşar, M.D. Haseki Egitim ve Arastirma Hastanesi, Istanbul, Turkey

Phone (Telefon): +90 5555816677 E-mail (E-posta): dr.tolgaavsar@gmail.com

Submitted Date (Başvuru Tarihi): 08.05.2018 Accepted Date(Kabul Tarihi): 23.05.2018

Copyright 2018 Haydarpaşa Numune Medical Journal

This is an open access article under the CC BY-NC license (http://creativecommons.org/licenses/by-nc/4.0/). 
in the hotel room where the patient was lying unconscious in bed before she was brought to our hospital.

Central venous pressure level was found to be $15 \mathrm{~cm} \mathrm{H}_{2} \mathrm{O}$. Some of the patient's parameters were as follows: arterial blood gas, $\mathrm{pH}$ 7.18; $\mathrm{PCO}_{2^{\prime}} 41 \mathrm{~mm} \mathrm{Hg} ; \mathrm{PO}_{2^{\prime}} 94 \mathrm{~mm} \mathrm{Hg}$; $\mathrm{SpO}_{2^{\prime}}$ 99\%; $\mathrm{HCO}_{3}, 15 \mathrm{mmol} / \mathrm{L}$; and base excess, $-13 \mathrm{mmol} / \mathrm{L}$ and Acute Physiologic Assessment and Chronic Health Evaluation II score, 14 points. Hypertonic 3\% saline therapy was initiated when serum sodium value was $107 \mathrm{mmol} / \mathrm{L}$, and the presence of cerebral edema accompanied by seizures was evaluated as encephalopathy developing as a result of polydipsia in consideration of the specific patient history.

Hypertonic saline administration was terminated when her serum sodium level increased $>120 \mathrm{mmol} / \mathrm{L}$. We ensured that the plasma sodium level increased at a rate of $<0.5$ $\mathrm{mEq} / \mathrm{L} / \mathrm{h}$. At $13 \mathrm{~h}$, she regained consciousness and spontaneous respiration, and her hemodynamic state was stabilized. Then, the patient was extubated and monitored under oxygen delivery with a mask. On day 3 of ICU stay, the patient had a sodium value of $135 \mathrm{mmol} / \mathrm{L}$ and a stable hemodynamic state, so she was transferred to a regular room in the service.

\section{Discussion}

Polydipsia is water intake of $\geq 3 \mathrm{~L}$ /day ${ }^{[3]}$. Water intoxication may result in muscle cramps, headache, confusion, lethargy, delirium, seizures, and coma. Brain edema and coma may lead to a fatal course. Encephalopathy and neurological symptoms begin when the plasma sodium concentration decreases acutely to $<125 \mathrm{mmol} / \mathrm{L}^{[8]}$.

Researchers suggested that polydipsia is caused by anticholinergic side effects of the psychiatric drugs used by the patient, whereas other researchers thought that psychotic exacerbations may be correlated with polydipsia [9]

Water intake and $\mathrm{ADH}$ release after feeling thirsty are controlled by the medial temporal lobe of the brain.

Elevation of ADH levels is known to cause psychotic exacerbations in patients with schizophrenia ${ }^{[10]}$. The limitation of this case presentation was that we did not examine the ADH levels of our patient in the clinical follow-up.

The lateral hypothalamus is a thirst center, and dopamine is an important neurotransmitter in this area. In animal studies, dopaminergic activity has been shown to be associated with polydipsia ${ }^{[11]}$.

The evaluation and treatment of polydipsic hyponatremia is very difficult, and chronic patients generally may not adapt to fluid restriction ${ }^{[3]}$. The use of antipsychotics in the treatment of polydipsia is also debatable because they both improve and cause polydipsia ${ }^{[12]}$.

We examined previous studies on water intoxication and related development of encephalopathy in patients with schizophrenia. Rao et al. (2011) [5] reported that they treated these cases with water restriction and low dose risperidone. Their patient was receiving $8 \mathrm{~L}$ of water every day. Similarly, Dirican et al. (2005) ${ }^{[8]}$ treated a patient with mental retardation and atypical psychosis with water restriction. Fluid restriction is often sufficient in the treatment of water intoxication. However, it is recommended that hypertonic saline solution should be administered in emergency cases.

Ventricular arrhythmia developed in a case of water intoxication in the study by Bayır et al. (2012) ${ }^{[13]}$ that did not occur in our case.

We should keep polydipsia in mind in psychiatric diseases. Hyponatremia due to polydipsia can lead to fatal outcomes. Careful treatment of hyponatremia is important.

\section{Conclusion}

In psychiatric disorders, psychological polydipsia, which means that a large amount of water is consumed in a short time due to schizophrenia in particular, is frequently seen, and this can lead to hyponatremic encephalopathy, which is sometimes a risk of morbidity and mortality. This entity that may lead to headache, nausea, vomiting, cerebral edema, encephalopathy, seizures, and even death requires close follow-up and vigorous treatment based on clinical and biochemical parameters.

Informed Consent: Approval was obtained from the patients. Peer-review: Externally peer-reviewed.

Conflict of Interest: None declared.

Authorship Contributions: Concept: M.T.A., I.A.; Design: M.T., M.T.A.; Data Collection or Processing: M.T.A., M.T., I.A.; Analysis or Interpretation: M.T.A., I.A.; Literature Search: I.A., M.T.A.; Writing: M.T.A., M.T., I.A.

Financial Disclosure: The authors declared that this study received no financial support.

\section{References}

1. Costanzo ES, Antes LM, Christensen AJ. Behavioral and medical treatment of chronic polydipsia in a patient with schizophrenia and diabetes insipidus. Psychosom Med 2004;66:283-6. [CrossRef]

2. Mercier-Guidez E, Loas G. Polydipsia and water intoxication in 353 psychiatric inpatients: an epidemiological and psychopathological study. Eur Psychiatry 2000;15:306-11. [CrossRef]

3. de Leon J, Verghese C, Tracy Jl, Josiassen RC, Simpson GM. Polydipsia and water intoxication in psychiatric patients: 
a review of the epidemiological literature. Biol Psychiatry 1994;35:408-19. [CrossRef]

4. Hiramatsu R, Takeshita A, Taguchi M, Takeuchi Y. Symptomatic hyponatremia after voluntary excessive water ingestion in a patient without psychiatric problems. Endocr J 2007;54:643-5.

5. Vishwajeet S, Aneesh S. Water intoxication leading to hyponatremia and seizures: a rare complication of uroflowmetry. Int Urol Nephrol 2005;37:275-6. [CrossRef]

6. Leadbetter RA, Shutty MS Jr, Higgins PB, Pavalonis D. Multidisciplinary approach to psychosis, intermittent hyponatremia, and polydipsia. Schizophr Bull 1994;20:375-85. [CrossRef]

7. Vieweg WV, Weiss NM, David JJ, Rowe WT, Godleski LS, Spradlin WW. Treatment of psychosis, intermittent hyponatremia, and polydipsia (PIP syndrome) using lithium and phenytoin. Biol Psychiatry 1988;23:25-30. [CrossRef]

8. Ceyhan Dirican A, Altunkaynak Y, Çelik S, Mutluay B, Coşkun K, Köksal A, Baybaş S. Psychogenic polydipsia associated with hyponatremic encephalopathy: A case report [Article in Turk- ish]. Cerrahpaşa J Med 2005;36:221-3.

9. Altındağ A, Yanık M, Nebioğlu M. Psychogenic polydipsia in bipolar disorder: A case report [Article in Turkish]. Bull Clin Psychopharmacol 2004;14:79-82.

10. Luchins DJ, Nettles KW, Goldman MB. Anterior medial temporal lobe volumes in polydipsic schizophrenic patients with and without hypo-osmolemia: a pilot study. Biol Psychiatry 1997;42:767-70. [CrossRef]

11. Mittleman G, Rosner AL, Schaub CL. Polydipsia and dopamine: behavioral effects of dopamine D1 and D2 receptor agonists and antagonists. J Pharmacol ExpTher 1994;271:638-50.

12. Bersani G, Pesaresi L, Orlandi V, Gherardelli S, Pancheri P. Atypical antipsychotics and polydipsia: a cause or a treatment? Hum Psychopharmacol 2007;22:103-7. [CrossRef]

13. Türker Bayır P, Demirkan B, Duyuler S, Güray Ü, Kısacık HL. Water Intoxication Resulting in Ventricular Arrythmias. Tr J Emerg Med 2012;12:188-190. [CrossRef] 